\title{
Effect of Rivastigmine on Mobility of Patients with Higher-Level Gait Disorder: A Pilot Exploratory Study
}

\author{
Tanya Gurevich · Yacov Balash • Doron Merims • \\ Chava Peretz · Talia Herman · Jeffrey M. Hausdorff • \\ Nir Giladi
}

Published online: 11 April 2014

(C) The Author(s) 2014. This article is published with open access at Springerlink.com

\begin{abstract}
Background Higher-level gait disorder (HLGD) in older adults is characterized by postural instability, stepping dysrhythmicity, recurrent falls and progressive immobility. Cognitive impairments are frequently associated with HLGD.

Objectives The aim of this study was to compare gait and cognitive performance before and after the use of rivastigmine in patients with HLGD, free from cognitive impairment or Parkinsonism.

Methods Fifteen non-demented patients with HLGD (age $79.2 \pm 5.9$ years; 11 women; Mini-Mental State

T. Gurevich $(\bowtie) \cdot$ Y. Balash · T. Herman .

J. M. Hausdorff · N. Giladi

Movement Disorders Unit, Department of Neurology, Tel Aviv

Medical Center, 6 Weizman Street, Tel Aviv 64239, Israel

e-mail: tanyag@tlvmc.gov.il

T. Gurevich · Y. Balash · J. M. Hausdorff · N. Giladi

Sackler School of Medicine, Tel-Aviv University, Tel Aviv, Israel

D. Merims

Shoham Medical Center for Geriatric Medicine, Tel Aviv, Israel

C. Peretz

School of Public Health, Sackler Faculty of Medicine, Tel-Aviv

University, Tel Aviv, Israel

T. Herman · J. M. Hausdorff

Laboratory of Gait and Neurodynamics, Department of

Neurology, Tel-Aviv Sourasky Medical Center, Tel Aviv, Israel

J. M. Hausdorff

Harvard Medical School, Boston, MA, USA

J. M. Hausdorff · N. Giladi

Sagol School of Neuroscience, Tel Aviv University, Tel Aviv, Israel
\end{abstract}

Examination [MMSE] $28.3 \pm 1.4)$ received escalating doses of rivastigmine for 12 weeks in an open-label, pilot study. They were assessed before and after treatment (week 0 and week 12), and after a 4-week washout period (week 16). Assessments included the Mindstreams computerized neuropsychological battery, Activities-specific Balance Confidence Scale, State-Trait Anxiety Inventory, Geriatric Depression Scale, Timed Up and Go (TUG) test, gait speed and stride time variability. One-way multiple analysis of variance tests for repeated measures were used, and Pillai's trace test was considered as robust to investigate significant differences.

Results The mean dose of rivastigmine during the 8-12 week period was $5.1 \pm 2.3 \mathrm{mg} /$ day. A positive effect was observed on the Mindstreams memory subscale and anxiety scores [Pillai's trace: $F(6,724)=0.508, p=0.010$; and $F(7,792)=0.545, p=0.006$, respectively, over the course of the study] as well as on mobility (TUG test) [Pillai's trace: $F(4,863)=0.448 ; p=0.028$ ], whereas gait speed and stride time variability did not change.

Conclusions The use of relatively low-dose rivastigmine did not affect gait speed and stride time variability; however, the general mobility and anxiety were improved. These preliminary results warrant a larger, randomized, placebo-controlled study.

\section{Introduction}

Higher-level gait disorder (HLGD) is a progressive multifactorial disorder in elderly adults, characterized by slow gait, stepping dysrhythmicity, postural instability, recurrent falls, progressive immobility, wheelchair use and institutionalization [1-5]. The pathophysiology of gait and balance impairment in people with HLGD is poorly 
understood and cannot be explained by motor, sensory, pyramidal, extrapyramidal, cerebellar, autonomic or peripheral disturbances [2].

Cognitive functions play an important role in the regulation of walking, particularly in older adults where deficits in executive functions and attention are independently associated with postural instability, impairments in daily living activities, and falls [6, 7]. In support of this idea, acetylcholinesterase inhibitors, cognitive enhancer medications for symptomatic treatment of patients with Alzheimer's and Parkinson's diseases, were found to reduce gait variability [8], and increase gait velocity $[9,10]$, in patients with Alzheimer's disease $[9,10]$, and to reduce fall risks in patients with Alzheimer's disease and in nondemented patients with Parkinson's disease $[9,10]$.

Two additional, randomized controlled, double-blind trials examining the effect of cholinesterase inhibitors on gait in a larger cohort of individuals with mild cognitive impairment [11] and in non-demented patients with Parkinson's disease are currently recruiting patients [12]. The aim of this study was to evaluate the effect of rivastigmine, an inhibitor of both butyrylcholinesterase and acetylcholinesterase, on locomotion and cognitive functions in elderly patients with HLGD who are free from cognitive or other motor impairments in an open-label, pilot exploratory study. Cholinergic agents affect many aspects of cognition, which suggests that the primary effect may be on an attention or executive system with a secondary modulating influence on memory, language, and visuospatial skills; improvement in attention may further reduce apathy. Cholinesterase inhibitors may play an important role in controlling neuropsychiatric and behavioral disturbances in patients, i.e. depression, anxiety, disinhibition and agitation [13]. The midbrain mesencephalic locomotor region (MLR), comprising the pedunculopontine (PPN) and cuneiform nuclei $(\mathrm{CN})$ [14], has recently been highlighted as an important region with respect to gait and balance disorders $[15,16]$.

On the basis of these data, together with the fact that specific lesions of the cholinergic PPN neurons in monkeys induce gait and postural deficits [17], we hypothesized that cholinergic deficit may contribute to the gait and balance disorders presented by HLGD patients, and that cholinesterase inhibitors could improve balance and reduce falls in subjects with HLGD.

\section{Methods}

\subsection{Subjects}

Twenty consecutive consenting patients with HLGD (14 women, age range 69-89 years, mean $79.6 \pm 6.1$ years) who attended our Movement Disorders Unit were originally enrolled in this pre-post intervention study. These patients were diagnosed as having HLGD by three movement disorders specialists (NG, TG and DM) using criteria described previously [2]. Any other causes for their gait difficulties were excluded in the clinical evaluation. All 20 subjects were able to walk independently for at least $30 \mathrm{~m}$. Those who were on a stable dose of other medications for at least 1 month prior to the baseline assessment agreed not to change their medications during the 16 weeks of the current study. Patients diagnosed as having dementia according to Diagnostic and Statistical Manual of Mental Disorders, 4th edition (DSM-IV) criteria and Mini-Mental State Examination (MMSE) scores less than 26 were excluded, as were those with clinically significant depression, orthopedic problems and any other neurological abnormalities that could have had an effect on gait and postural responses. Patients with a history of severe head trauma or stroke and those with significant structural brain lesions on computerized tomography or with clinically significant orthostatic hypotension were also excluded. In addition, we excluded patients with active malignancy, uncontrolled symptomatic heart disease, diabetes mellitus or hypertension, as well as those with psychiatric disorders. All of the enrolled patients had normal vitamin $B_{12}$, folic acid, as well as general hematology, electrolytes, renal and liver function tests, and a negative venereal disease research laboratory (VDRL) test. The study was approved by the Ethics Committee of the Tel Aviv Medical Center, and each patient signed an informed consent form prior to enrolling in the study.

\subsection{Drug Escalation}

Rivastigmine was given orally at an initial dose of $1.5 \mathrm{mg}$ twice daily. This dose was increased to $3 \mathrm{mg}$ twice daily after 4 weeks, and to $4.5 \mathrm{mg}$ twice daily after 8 weeks. Patients who developed side effects at any stage were either left on the same dose for 2 or more weeks or had their daily dose reduced to the previous level. We tried to keep the dose of rivastigmine constant at the maximal tolerated dose between week 8 and week 12 of the trial, the point at which administration of the drug was stopped.

\subsection{Clinical Evaluations}

The patients were assessed at baseline (week 0), shortly after the termination of rivastigmine medication (week 12), and after a 4-week washout period (week 16). Each assessment included evaluation of the subject's general condition together with registration of vital functions and side effects. Also included were the scores of the MMSE [18], the short form of the Geriatric Depression Scale 
(GDS) [19], the Activities-specific Balance Confidence scale (ABC) for measuring the level of fear of falling [20], and the State-Trait Anxiety Inventory (STAI) [21]. Cognitive performance was assessed using Mindstreams, a computerized neuropsychological battery, which includes tests for the domains of memory, attention, executive, visual-spatial functions and global cognitive function [22]. All cognitive scores in Mindstreams are normalized, where 100 is the mean and one SD is 15 points for matched age and education levels (we therefore used cutoff scores $<85$ to denote impairment).

\subsection{Gait Assessment}

The Timed Up and Go (TUG) test [23] was administered for a general assessment of balance, mobility, lower extremity function, and fall risk [24, 25]. A computerized force-sensitive system was used to quantify gait and strideto-stride variability [26]. The system measures the forces underneath the foot as a function of time and consists of a pair of insoles (footswitch) and a recording unit. Each insole contains four load sensors that cover the surface of the sole and measure the normal (vertical) forces under the foot. A small recording unit $(11.5 \times 6.5 \times 3.5 \mathrm{~cm} ; 0.5 \mathrm{~kg})$ is carried on the subject's waist. Plantar pressures under each foot are recorded at a rate of $100 \mathrm{~Hz}$. Measurements are stored in a memory card during the walk, after which they are transferred to a personal computer for further analysis. Average stride time and stride time variability were determined from the recorded force using previously described methods [27, 28]. Variability measures were quantified by means of the coefficient of variation, e.g. stride-time variability $=100 \times$ (average stride time/standard deviation).

\subsection{Statistics}

The descriptive step included a calculation of mean and standard deviation. All numeric variables were analyzed using repeated measures. One-way multiple analysis of variance (MANOVA) was used to compare the three assessments on weeks 0,12 , and 16 . In all cases, the post hoc Pillai's trace test was considered as robust to investigate significant differences. The results were evaluated in a confidence interval range of $95 \%$ and a significance level of $p<0.05$. Statistical analysis was performed using SPSS statistical software (SPSS, Chicago, IL, USA).

\section{Results}

The 20 enrolled patients had suffered from gait disorders for $3.9 \pm 3.6$ years before enrolling in the study. Three patients dropped out at weeks 3-4 into the study due to general weakness, fatigue, insomnia and/or non-compliance while on a dose of $1.5 \mathrm{mg}$ twice daily. Two patients stopped escalation of rivastigmine at 3-4 weeks, while on a stable dose of $3.0 \mathrm{mg}$, because of dizziness, vertigo, nausea, blurred vision, diarrhea, general weakness and/or fatigue, which completely disappeared following dose lowering. Fifteen patients (mean age $79.2 \pm 5.9$ years, range $72-89$ years, 11 women) completed the study. The mean rivastigmine dose at study closure (week 12) was $5.1 \pm 2.3 \mathrm{mg}$ (range $3.0-9.0 \mathrm{mg}$ ). The effects of rivastigmine on mental functions, affect and gait are presented in Table 1.

The mean Mindstreams memory subscale scores consistently improved, from $85.7 \pm 9.6$ at baseline to $88.97 \pm 6.6$ at week 12 , and further to $93.9 \pm 13.1$ at week 16 [Pillai's trace $F(6,724)=0.508 ; p=0.010$ ]. The size effect of rivastigmine on the memory subscale was considerable, exceeding 10 points, in 12 patients (80\%).

The mean anxiety scores according to the STAI scale improved from $37.5 \pm 7.6$ points at baseline to $34.3 \pm 8.1$ points at the end of the medication period (week 12), returning to $38.5 \pm 10$ points after washout (week 16) [Pillai's trace $F(7,792)=0.545 ; p=0.006$ ].

Locomotion and mobility significantly improved according to the TUG test, changing from $14.1 \pm 3.8 \mathrm{~s}$ at baseline to $13.1 \pm 2.4 \mathrm{~s}$ at week 12 and $13.5 \pm 2.5 \mathrm{~s}$ at week 16, indicating a significant beneficial drug effect [Pillai's trace $F(4,863)=0.448 ; p=0.028$ ]. In contrast, rivastigmine treatment had no effect on MMSE, ABC and GDS scores, and other (non-memory) Mindstreams domains, as well as on gait speed and stride-time variability (Table 1).

\section{Discussion}

HLGD is a disease of old age resulting in restriction of mobility and often accompanied by cognitive decline [29]. The association between cognitive decline and mobility impairments in the elderly is now well established [30], and abnormal gait itself is an early marker for future cognitive decline [31]. The present pilot study was an open-labeled exploratory trial that suggested a possible positive rivastigmine effect on cognitive and motor function. The benefits of rivastigmine, if confirmed in future studies, can be attributed to its effect on affect (anxiety) and/or cognition (executive functions). Decrease of the anxiety level with rivastigmine treatment has also been reported in patients with Alzheimer's disease [32].

Rivastigmine's treatment association with shortening of the TUG test may be indicative of improved mobility, stability, and decrease in fall risk in patients with HLGD. 
Table 1 Effects of rivastigmine on cognitive characteristics and gait parameters in 15 patients with higher-level gait disorder

\begin{tabular}{|c|c|c|c|c|}
\hline & $\begin{array}{l}\text { Baseline, week } 0 \\
(n=15)\end{array}$ & $\begin{array}{l}\text { After treatment, week } 12 \\
(n=15)\end{array}$ & $\begin{array}{l}\text { Washout after treatment, week } 16 \\
(n=15)\end{array}$ & Pillai's trace test \\
\hline $\begin{array}{l}\text { Mean rivastigmine dose }(\mathrm{mg} / \\
\text { day) }\end{array}$ & 0 & $5.1 \pm 2.3$ & 0 & \\
\hline MMSE & $28.3 \pm 1.4$ & $28.13 \pm 1.1$ & $28.4 \pm 1.4$ & NS \\
\hline $\begin{array}{l}\text { Mindstreams global } \\
\text { cognitive score }\end{array}$ & $90.43 \pm 7.1$ & $91.52 \pm 7.5$ & $93.47 \pm 9.8$ & NS \\
\hline Memory subscale & $85.75 \pm 9.6$ & $88.97 \pm 6.6$ & $93.98 \pm 13.1$ & $\begin{array}{l}F(6,724)=0.508 ;^{\mathrm{a}} \\
\quad p=0.010\end{array}$ \\
\hline Anxiety subscale & $37.46 \pm 7.6$ & $34.26 \pm 8.1$ & $38.53 \pm 10.0$ & NS \\
\hline Executive function subscale & $90.10 \pm 8.5$ & $90.56 \pm 8.4$ & $92.72 \pm 8.7$ & NS \\
\hline Visuospatial subscale & $86.49 \pm 11.0$ & $86.99 \pm 15.8$ & $86.6 \pm 12.7$ & NS \\
\hline Attention subscale & $92.48 \pm 14.9$ & $96.29 \pm 12.7$ & $98.19 \pm 12.8$ & NS \\
\hline $\mathrm{ABC}$ (fear of falling) scale & $68.3 \pm 12.6$ & $69.7 \pm 16.0$ & $65.7 \pm 17.8$ & NS \\
\hline $\begin{array}{l}\text { STAI (Spielberger Anxiety } \\
\text { Inventory) }\end{array}$ & $37.5 \pm 7.6$ & $34.3 \pm 8.1$ & $38.5 \pm 10$ & $\begin{array}{l}F(7,792)=0.545 \\
\quad p=0.006\end{array}$ \\
\hline Geriatric Depression Scale & $9.4 \pm 5.7$ & $9.07 \pm 5.3$ & $10.26 \pm 5.8$ & NS \\
\hline Timed Up and Go test (s) & $14.1 \pm 3.8$ & $13.1 \pm 2.4$ & $13.5 \pm 2.5$ & $\begin{array}{l}F(4,863)=0.448 \\
\quad p=0.028\end{array}$ \\
\hline Gait speed $(\mathrm{m} / \mathrm{s})$ & $0.86 \pm 0.8$ & $0.90 \pm 0.1$ & $0.90 \pm 0.2$ & NS \\
\hline Stride-time variability (\%) & $3.65 \pm 1.3$ & $3.29 \pm 1.0$ & $3.36 \pm 1.3$ & NS \\
\hline
\end{tabular}

MMSE Mini-Mental State Examination, NS not significant, ABC Activities-specific Balance Confidence scale, STAI State-Trait Anxiety Inventory

${ }^{\text {a }} F$ indicates variance analysis of repeated measurements

The TUG test requires a transfer from sitting to standing, walking and turning, and is influenced by walking speed, muscle strength and balance [33, 34]. The TUG test is a sensitive and specific measure for identifying communitydwelling adults who are at risk for falls [35]. Time to completion above $14 \mathrm{~s}$ indicates a high risk of falls in the elderly population $[25,36]$.

Timing of the TUG test also reflects cognitive abilities, given its independent association with better performance on global cognition, memory tests and faster processing speed in community-dwelling adults older than 50 years of age [37]. Earlier studies reported that rivastigmine had significantly improved executive function on tests for flexibility of thinking, problem solving and planning in patients with parkinsonian dementia [38, 39]. Our results have not demonstrated an effect on executive functions, probably because of a ceiling effect. The same explanation probably applies to the lack of effect on MMSE, attention and visuospatial skills. These findings support the hypothesis that rivastigmine may affect frontal subcortical circuits in parkinsonian patients [39], although we did not observe any improvement of executive functions in the present study. The limited effect of rivastigmine on gait that had been observed in the present study may have been caused by the comparatively low doses of the medicament. Nevertheless, it was accompanied by considerable adverse effects. Advanced patch delivery transdermal systems containing larger doses of rivastigmine may be more effective because of the stable rivastigmine plasma levels and better tolerability [40].

Limitations of this study include the small number of participants, making the power of this study low, and its open-label design (allowing training or a placebo effect on mobility as well as on anxiety).

Although we did not employ a blinded evaluator, it ought to be outlined that the present study included mainly the Mindstreams computerized tests as an endpoint, and that the target kinematic measures were generated automatically. Placebo-controlled studies with larger doses of rivastigmine are needed to determine the possibility of further improvements of locomotion and better performance of activities of daily living in elderly individuals with HLGD.

\section{Conclusions}

The findings of this exploratory, small, open-label study indicate a possible positive effect of rivastigmine on anxiety and mobility in patients with HLGD. The possibility that the drug will have the capability to prevent falls and maintain independent mobility justifies a large-scale, placebo-controlled clinical trial with a calculation of a theoretical number needed to show a result in advance. 
Acknowledgments This study was partially supported in part by Novartis Israel Ltd and by a research grant from Neurotrax Corporation Ltd. The sponsors were not involved in the design, interpretation or writing of the manuscript.

Disclosures Tanya Gurevich, Yacov Balash, Doron Merims, Chava Peretz, Talia Herman, Jeffrey M. Hausdorff, and Nir Giladi have no conflicts of interest that are relevant to this study.

Open Access This article is distributed under the terms of the Creative Commons Attribution Noncommercial License which permits any noncommercial use, distribution, and reproduction in any medium, provided the original author(s) and the source are credited.

\section{References}

1. Sudarsky L. Geriatrics: gait disorders in the elderly. N Engl J Med. 1990;322:1441-6.

2. Nutt JG, Marsden CD, Thompson PD. Human walking and higher-level gait disorders, particularly in the elderly. Neurology. 1993;43:268-79.

3. Herman T, Giladi N, Gurevich T, Hausdorff JM. Gait instability and fractal dynamics of older adults with a "cautious" gait: why do certain older adults walk fearfully? Gait Posture. 2005;21:178-85.

4. Peretz C, Herman T, Hausdorff JM, Giladi N. Assessing fear of falling: can a short version of the Activities-specific Balance Confidence scale be useful? Mov Disord. 2006;21:2101.

5. Huber-Mahlin V, Giladi N, Herman T, Perez C, Gurevich T, Hausdorff JM. Progressive nature of a higher level gait disorder: a 3-year prospective study. J Neurol. 2010;257:1279-86.

6. Yogev-Seligmann G, Hausdorff JM, Giladi N. The role of executive function and attention in gait. Mov Disord. 2008;23:329-42.

7. Hausdorff JM, Yogev G, Springer S, Simon ES, Giladi N. Walking is more like catching than tapping: gait in the elderly as a complex cognitive task. Exp Brain Res. 2005;164:541-8.

8. Assal F, Allali G, Kressig RW, Herrmann FR, Beauchet O. Galantamine improves gait performance in patients with Alzheimer's disease. J Am Geriatr Soc. 2008;56:946-7.

9. Montero-Odasso M, Wells J, Borrie M. Can cognitive enhancers reduce the risk of falls in people with dementia? An open-label study with controls. J Am Geriatr Soc. 2009;57:359-60.

10. Chung KA, Lobb BM, Nutt JG, Horak FB. Effects of a central cholinesterase inhibitor on reducing falls in Parkinson disease. Neurology. 2010;75:1263-9.

11. Montero-Odasso M, Wells JL, Borrie MJ, Speechley M. Can cognitive enhancers reduce the risk of falls in older people with mild cognitive impairment? A protocol for a randomised controlled double blind trial. BMC Neurol. 2009;9:42.

12. Henderson EJ, Lord SR, Jacqueline CT, Close JCT, Lawrence $\mathrm{AD}$, Whone E, Ben-Shlomo Y. The ReSPonD trial: rivastigmine to stabilise gait in Parkinson's disease a phase II, randomised, double blind, placebo controlled trial to evaluate the effect of rivastigmine on gait in patients with Parkinson's disease who have fallen. BMC Neurol. 2013;13:188.

13. Cummings JL. Cholinesterase inhibitors: a new class of psychotropic compounds. Am J Psychiatry. 2000;157(1):4-15.

14. Nutt JG, Horak FB, Bloem BR. Milestones in gait, balance, and falling. Mov Disord. 2011;26:1166-74.

15. Chastan N, Do MC, Bonneville F, Torny F, Bloch F, Westby GW, et al. Gait and balance disorders in Parkinson's disease: impaired active braking of the fall of centre of gravity. Mov Disord. 2009;24:188-95.

16. Snijders AH, Leunissen I, Bakker M, Overeem S, Helmich RC, Bloem BR, Toni I. Gait-related cerebral alterations in patients with Parkinson's disease with freezing of gait. Brain. 2011;134:59-72.

17. Karachi C, Grabli D, Bernard FA, Tandé D, Wattiez N, Belaid H. Cholinergic mesencephalic neurons are involved in gait and postural disorders in Parkinson disease. J Clin Investig. 2010;120:2745-54.

18. Folstein MF, Folstein SE, McHugh PR. "Mini-mental state". A practical method for grading the cognitive state of patients for the clinician. J Psychiatr Res. 1975;12:189-98.

19. Shiekh J, Yesavage J. Geriatric Depression Scale: recent findings and development of a short version Clinical Gerontology: a guide to assessment and intervention. New York: Howard Press; 1986.

20. Powell LE, Myers AM. The Activities-specific Balance Confidence (ABC) scale. J Gerontol A Biol Sci Med Sci. 1995;50A:M28-34.

21. Spielberger CD, Gorsuch RL, Kushene RP, Vagg R, Jacobs GA. State-trait anxiety inventory: self-evaluation questionnaire (form y) In: Spielberger CD, editor. Manual for the State-Trait Anxiety Inventory. Palo Alto: Consulting Psychologist Press; 1983

22. Dwolatzky T, Whitehead V, Doniger GM, Simon ES, Schweiger A, Jaffe D, et al. Validity of the Mindstreams computerized cognitive battery for mild cognitive impairment. J Mol Neurosci. 2004;24:33-44.

23. Podsiadlo D, Richardson S. The timed "Up \& Go": a test of basic functional mobility for frail elderly persons. J Am Geriatr Soc. 1991;39:142-8.

24. Okumiya K, Matsubayashi K, Nakamura T, Fujisawa M, Osaki Y, Doi Y, et al. The timed "up \& go" test is a useful predictor of falls in community-dwelling older people. J Am Geriatr Soc. 1998;46:928-30.

25. Shumway-Cook A, Brauer S, Woollacott M. Predicting the probability for falls in community-dwelling older adults using the Timed Up \& Go test. Phys Ther. 2000;80:896-903.

26. Hausdorff JM, Nelson ME, Kaliton D, Layne JE, Bernstein MJ, Nuernberger A, et al. Etiology and modification of gait instability in older adults: a randomized controlled trial of exercise. J Appl Physiol. 2001;90:2117-29.

27. Hausdorff JM, Rios DA, Edelberg HK. Gait variability and fall risk in community-living older adults: a 1-year prospective study. Arch Phys Med Rehabil. 2001;82:1050-6.

28. Frenkel-Toledo S, Giladi N, Peretz C, Herman T, Gruendlinger L, Hausdorff JM. Treadmill walking as an external pacemaker to improve gait rhythm and stability in Parkinson's disease. Mov Disord. 2005;20:1109-14.

29. Giladi N, Huber-Mahlin V, Herman T, Hausdorff JM. Freezing of gait in older adults with high level gait disorders: association with impaired executive function. J Neural Transm. 2007;114: 1349-53.

30. Buchman AS, Boyle PA, Leurgans SE, Barnes LL, Bennett DA. Cognitive function is associated with the development of mobility impairments in community-dwelling elders. Am J Geriatr Psychiatry. 2011;19:571-80.

31. Verghese J, Lipton RB, Hall CB, Kuslansky G, Katz MJ, Buschke H. Abnormality of gait as a predictor of non-Alzheimer's dementia. N Engl J Med. 2002;347:1761-8.

32. Gauthier S, Juby A, Dalziel W, Réhel B, Schecter R. EXPLORE investigators. Effects of rivastigmine on common symptomatology of Alzheimer's disease. Curr Med Res Opin. 2010;26: 1149-60.

33. Weiss A, Herman T, Plotnik M, Brozgol M, Giladi N, Hausdorff JM. An instrumented timed up and go: the added value of an 
accelerometer for identifying fall risk in idiopathic fallers. Physiol Meas. 2011;32:2003-18.

34. Herman T, Giladi N, Hausdorff JM. Properties of the 'timed up and go' test: more than meets the eye. Gerontology. 2011;57:203-10.

35. Nordin E, Lindelöf N, Rosendahl E, Jensen J, Lundin-Olsson L. Prognostic validity of the Timed Up-and-Go test, a modified GetUp-and-Go test, staff's global judgement and fall history in evaluating fall risk in residential care. Age Ageing. 2008;37:442-8.

36. Mirelman A, Herman T, Brozgol M, Dorfman M, Sprecher E, Schweiger A, et al. Executive function and falls in older adults: new findings from a five-year prospective study link fall risk to cognition. PLoS One. 2012; 7:e40297.
37. Donoghue OA, Horgan NF, Savva GM, Cronin H, O'Regan C, Kenny RA. Association between timed up-and-go and memory, executive function, and processing speed. J Am Geriatr Soc. 2012;60:1681-6.

38. Giladi N, Shabtai H, Gurevich T, Benbunan B, Anca M, Korczyn AD. Rivastigmine (Exelon) for dementia in patients with Parkinson's disease. Acta Neurol Scand. 2003;108:368-73.

39. Schmitt FA, Farlow MR, Meng X, Tekin S, Olin JT. Efficacy of rivastigmine on executive function in patients with Parkinson's disease dementia. CNS Neurosci Ther. 2010;16:330-6.

40. Kurz A, Farlow M, Lefèvre G. Pharmacokinetics of a novel transdermal rivastigmine patch for the treatment of Alzheimer's disease: a review. Int J Clin Pract. 2009;63:799-805. 